\title{
12. A OBRA ADMIRÁVEL MUNDO NOVO E A PROTEÇÃO DE DIREITOS FUNDAMENTAIS NO ESTADO DEMOCRÁTICO DE DIREITO A PARTIR DA CONCEPÇÃO DE RONALD DWORKIN
}

\section{THE BRAVE NEW WORLD AND THE FUNDAMENTAL RIGHTS PROTECTION IN A DEMOCRATIC STATE FROM THE VISION OF RONALD DWORKIN}

\author{
Jaqueline Mielke Silva ${ }^{1}$
}

\begin{abstract}
RESUMO: Na obra da Aldous Huxley “Admirável Mundo Novo", o modelo de sociedade é construído a partir da violação de direitos fundamentais mínimos. O presente artigo tem o propósito de analisar a proteção de direitos fundamentais no Estado Democrático de Direito a partir da concepção de Direito do jurista americano Ronald Dworkin, que se opõe à sociedade retratada na obra "Admirável Mundo Novo".
\end{abstract}

PALAVRAS-CHAVE: admirável - mundo novo - direitos fundamentais - integridade - sociedade

ABSTRACT: In the work of Aldous Huxley's "Brave New World", the social model is built from the violation of minimum basic rights. This article aims to analyze the protection of fundamental rights in a democratic state from the conception of Law American jurist Ronald Dworkin, who opposes portrayed in the book "Brave New World" society.

KEYWORDS: admirable - new world - Fundamental rights - integrity society

\section{A violação de Dreitos Fundamentais mínimos na obra Admirável Mundo Novo de}

\section{Aldous Huxley}

A obra "Admirável Mundo Novo" (HUXLEY, 2009) é um clássico da literatura mundial. A mesma foi escrita por Aldous Huxley, na década de trinta. O objeto principal da obra são pessoas que foram geradas em laboratório, a partir e experimentos

\footnotetext{
${ }^{1}$ Doutora e Mestre em Direito pela Universidade do Vale do Rio dos Sinos. Especialista em Direito Processual Civil pela Pontifícia Universidade Católica do Rio Grande do Sul. Professora do Curso de Pósgraduação stricto sensu da Faculdade IMED e da Faculdade INEDI - CESUCA e de outras instituições de ensino superior. Professora na Escola Superior da Magistratura do Rio Grande do Sul - AJURIS, Escola Superior da Magistratura Federal - ESMAFE, Fundação Escola Superior do Ministério Público - FMP, Escola Superior da Magistratura do Trabalho - FEMARGS. Advogada. E-mail: jaqueline@mielkelucena.com.br
} 
químicos, realizados por máquinas de avançada tecnologia. Como consequência lógica, os perigos do progresso tecnológico são tratados igualmente, de forma bastante abrangente.

De acordo com a obra, consoante se extrai de um diálogo, do qual participa o senhor Foster, "quanto mais baixa é a casta, menos oxigênio se dá". Ou seja, na obra, constase evidente discriminação entre seres humanos, de "castas" diferentes. Essa discriminação ainda pode ser observada em inúmeros países, explícita, como por exemplo, na Índia ou, implicitamente, como ocorre em países ocidentais (v.g. no Brasil), onde ainda os negros são tratados veladamente de forma desigual.

Após explicar o procedimento para geração de humanos, o senhor Foster explica aos visitantes o procedimento que é utilizado para ensinar crianças recém nascidas ou com idades de 5 anos, a viver a vida neste mundo novo. Nesta passagem, observa-se uma das passagens mais cruéis da obra. Várias crianças eram colocadas em um grande cercado. Algumas começavam a engatinhar e outras ficavam assustadas e estáticas. Em seguida, começava a soar uma explosão violenta, seguida do som ensurdecedor de uma sirene. Em ato contínuo, as crianças começavam a gritar desesperadas com a situação. O terror estampado nas faces dos infantes era evidente. Para completar o ato de terrorismo, o diretor ordenava que fosse acionado o choque elétrico, onde todas eram atingidas e desmaiavam em seguida. Essas sessões eram repetidas diariamente, até que as crianças partissem para o lar de seus pais.

A violação a direitos fundamentais das crianças e adolescentes é evidente na obra de Aldous Huxley. No Brasil, o Estatuto da Criança e do Adolescente, dispõe no art. 227: "É dever da família, da sociedade e do Estado assegurar à criança, ao adolescente e ao jovem com absoluta prioridade, o direito à vida, à saúde, à alimentação, à educação, ao lazer, à cultura, à dignidade, ao respeito (...), além de colocá-los a salvo de toda forma de negligência, discriminação, violência, crueldade e opressão”. O art. $7^{\circ}$ do mesmo texto legal, por sua vez, dispõe que "a criança e adolescente têm direito a proteção à vida e à saúde, mediante a efetivação de políticas sociais públicas que permitam o nascimento e o desenvolvimento sadio e harmonioso, em condições dignas de existência”. Os expedientes nefastos utilizados na obra, objeto do presente ensaio, são terminantemente vedados em nosso ordenamento jurídico. Jamais prosperariam em nosso sistema jurídico, as condutas descritas. 
Por outro lado, o autor faz questão de lembrar que as crianças do admirável mundo novo eram em centros de condicionamento do Estado. Neste tópico, vem à tona o direito fundamental à liberdade de expressão. Os pais não têm/tinham o direito de educar/criar os filhos do modo que entendessem mais conveniente, sequer eram imaginados como nascidos naturalmente de uma relação afetiva, afinal, eram previamente planejados e produzidos em laboratório e a época em que nasciam de tais relações era considerada "vergonhosa" e antiquada.

A desmoralização da vida humana, com a evidente violação ao direito fundamental à vida, também é retratada na obra de Aldous Huxley. No decorrer do texto, refere que "o homicídio mata apenas o indivíduo. Nós podemos produzir um indivíduo novo com maior facilidade; tantos quantos quisermos. A falta de liberdade, porém, ameaça mais do que a vida de um simples indivíduo; ela atinge a própria sociedade”. Por esta passagem, observa-se que não era necessário repreender o homicídio, uma vez que poderia ser gerada uma nova vida na hora que fosse mais conveniente. Não havia laços afetivos e muito menos morais!

O indiscriminado uso de drogas, também é relatado na obra de Aldous Huxley. A sociedade vivia a base de uma substância conhecida como soma. O uso indiscriminado de drogas (soma!) é incentivado na obra, porque ela não trazia nenhuma consequência desagradável, proporcionando o esquecimento perfeito. Não é demasiado referir, que o pagamento do trabalho era com a droga "soma". Se o despertar era desagradável, não o era intrinsecamente, mas apenas em comparação com as alegrias desfrutadas. O propósito do uso da droga era tornar contínua a funda. Evidentemente, o seu uso reclamava doses cada vez mais fortes e frequentes. O vício era tamanho, que foi usado como meio de controlar as massas e os impulsos humanos. Uma excelente arma para o Estado controlar os cidadãos.

Em nosso sistema jurídico, há a proibição expressa de pagamentos por meio de drogas aos trabalhadores, no artigo 458 da Consolidação das Leis do Trabalho, verbis: "em caso algum será permitido o pagamento com bebidas alcoólicas ou drogas nocivas". Entretanto, a manipulação da população pelo Estado, muitas vezes é realizada pela imprensa, 
ou mesmo através da concessão de benefícios (bolsa família), que auxilia a mascarar os problemas reais pelos qual a população passa e precisa realmente enfrentar.

No admirável mundo novo, retratado por Aldous Huxley há também o Poder Judiciário, e o Presidente do Supremo Tribunal de Justiça. Havia uma justiça: a do Estado controlador! Do mesmo modo, constata-se a existência de uma sanção penal. Um afrodescendente que havia atacado por insanidade uma moça, foi enviado para um Centro de Recondicionamento de Adultos.

A liberdade de expressão também se revela violada na obra, quando em um dado momento o governante orientou que não fosse publicado um livro que contrariava toda a teoria biológica.

A questão da "soma" era algo tão nocivo e manipulador, que nos grandes conflitos sociais, a polícia jogava bombas de soma para acalmar e controlar a multidão ensandecida. Era uma prática parecida com aquela utilizada pela polícia, nos dias de hoje, quando usa bombas de efeito moral, com gás lacrimogêneo. Do mesmo modo, a droga é utilizada nos manicômios para deixar as pessoas completamente alheias à realidade.

\section{Os direitos fundamentais como trunfos no Estado Democrático de Direito}

A filosofia de Ronald DWORKIN (1995, p. 158 e ss.) tem por fundamento os direitos individuais. Isso significa que os direitos individuais - especialmente o Direito a igual consideração e respeito - são preponderantes frente à maioria. Nenhuma diretriz política nem objetivo social coletivo podem triunfar frente a um autêntico Direito.

Ronald DWORKIN (1995, p. 102 e ss.) propõe um novo modelo de decisão judicial, contrastante com os modelos tradicionais ${ }^{2}$ : o modelo da resposta certa. O juiz carece

\footnotetext{
${ }^{2}$ Modelos tradicionais: A) Modelo silogístico - defendido pelo formalismo jurídico. Segundo esta concepção, a tarefa do juiz é lógico-mecânica. O problema do juiz é a subsunção do caso a uma norma pré-estabelecida. Se não existe norma aplicável, o juiz deve rejeitar a demanda. No direito não existem casos difíceis, porque tudo o que não está proibido está permitido. A função do juiz está subordinada à lei. B) Modelo realista - defendido por muitas correntes antiformalistas. Segundo esse modelo, as decisões dos juízes são fruto de suas preferências pessoais e de sua consciência subjetiva. O juiz
} 
de discrição e, portanto, de poder político. A verdadeira resposta corresponde à teoria que é capaz de justificar, de melhor modo, os materiais jurídicos vigentes.

Ronald DWORKIN (1995, p. 102 e ss.) entende que a função dos tribunais, nos casos controversos, seria não a de criar um novo direito, mas a de descobrir o Direito que se acha oculto até então. Tal descobrimento se faria através dos princípios e das diretrizes ${ }^{3}$.

Os princípios, para Ronald DWORKIN (1995, p. 147), caracterizam-se com um conjunto de normas outras (que não regras jurídicas) no sentido do seu improvement econômico, político e social. O termo "princípio", em seu sentido específico, vai se opor à noção de política, ao dizer respeito a um tipo de norma cuja observação é um requisito de justiça e eqüidade ou, ainda, de alguma outra dimensão moral. A noção de política, por sua vez, diz respeito a um tipo de norma cujo objetivo é o bem-estar geral da comunidade. ${ }^{4}$

Eros Roberto GRAU (1988, p. 105) adota o critério tomado por Ronald DWORKIN, exemplificando com os seguintes dispositivos constitucionais:

Princípios - art. $1 .^{\circ}$, 'caput' e incisos; art. $2 .^{\circ}$; art. $4 .^{\circ}$; art. $5 .^{\circ}$, 'caput' e incisos; art. 170, 'caput' (parcialmente) e incisos;

Diretrizes - art. $3 .^{\circ}$, parágrafo único do art. $4 .^{\circ}$, art. 170 , 'caput' (parcialmente).

A propósito, aqui, já na primeira visualização do texto, verificamos que a dignidade da pessoa humana comparece, no art. $1 .^{\circ}$, III, como princípio, e, no art. 170, caput, como diretriz ('assegurar a todos existência digna').

Toda decisão jurídica cujo argumento esteja baseado em princípios atenderá a um direito individual; todavia, se o mesmo estiver baseado em políticas, atenderá a um fim coletivo, face ao bem-estar geral da comunidade. Segundo Ronald DWORKIN (1995, p. 150 e ss.), as decisões judiciais devem ser geradas por princípios, uma vez que tribunal e

primeiro decide e após justifica sua decisão mediante normas. O juiz tem poder político, não está subordinado à lei. Concede ao juiz um autêntico poder político que não é congruente com o sistema de legitimação do estado democrático nem com o postulado da separação de poderes. C) Modelo positivista da discrição judicial - este modelo reconhece a existência de casos difíceis, nos quais não existe norma aplicável. É defendido por Hart e Bobbio. Nos casos difíceis, o juiz exerce um poder discricionário. Para este modelo, o direito não oferece uma resposta correta, mas uma variedade de respostas possíveis. O juiz elege discricionariamente as mesmas. (DWORKIN, 1995, p. 20-21).

${ }^{3}$ Katya KOZICKI critica a posição de Ronald DWORKIN, afirmando que "não nos parece adequada tal colocação, uma vez que mesmo a adoção destes princípios e diretrizes é insuficiente para prover o sistema jurídico de forma a que este não apresente fissuras". (ROCHA, 1997, p. 149).

${ }^{4}$ Exemplificando: a determinação segundo a qual ninguém pode obter vantagem (lucro) através do seu próprio erro é uma norma que funciona como um princípio, enquanto a determinação segundo a qual acidentes de trânsito devem diminuir é uma norma que funciona como política. (CHUEIRI, 1995, p. 158). 
legislativo não se confundem: programas legislativos podem ser razoáveis e corretamente justificados por políticas.

Quando os juízes constroem regras não anteriormente reconhecidas, não estão eles livres no sentido em que o são os legisladores. Os juízes devem tomar suas decisões costumeiras apoiados em princípios e não em políticas. Devem desenvolver argumentos acerca do porquê as partes tinham, de fato, 'novos' direitos e deveres jurídicos, os quais eles exigem como cumpridos, quer no momento em que as partes agiram, quer em algum outro momento pertinente ao passado. Segundo Ronald DWORKIN (1986, p. 76),

Quando os juízes constroem regulamentações (...) não admitidas anteriormente, eles não têm total liberdade em seu modo de proceder. Os juízes devem tomar suas decisões sobre a lei ordinária com base em princípios, não em políticas: devem desenvolver os argumentos segundo os motivos pelos quais as partes sustentaram na realidade os seus "novel" (novéis) direitos e deveres legais que eles, os juízes, põem em vigor no momento de ação das partes, ou em algum outro momento pertinente já passado. 5

A argumentação de Ronald DWORKIN (1995, p. 147) apóia-se na sua tese dos direitos, ou seja, as decisões judiciais, especialmente nos casos difíceis e nos casos controversos, são - e deveriam ser - geradas por princípios. Essa tese assevera, na prática, a dimensão política do jurídico, na medida em que joga para as decisões judiciais o fazer valer ou fazer cumprir dos direitos políticos existentes: primeiro, ao lançar mão de um princípio, de um objetivo político individualizado, identificando, através do mesmo, a existência de um direito. Impera a moralidade pessoal do juiz - enquanto membro de uma instituição que comporta uma teoria política - através da sua argumentação baseada em princípios e a moralidade institucional contida no precedente.

A tese dos direitos distingue, objetivamente, direitos individuais e fins sociais. Os direitos individuais consistem em objetivos políticos individualizados, enquanto que os fins sociais consistem em objetivos políticos não-individualizados.

\footnotetext{
5 "'When judges construct rules (...) not recognized before, they are not free in the way (...) legislators are (...). Judges must make their common-law decisions on grounds of principle, not policy: they must deploy arguments why the parties actually had the 'novel' legal rights and duties they enforce at the time the parties acted or at some other pertinent time in the past." (DWORKIN, 1986, p. 76).
} 
Logo, é possível pensar em direitos jurídicos, ainda que se trate de um caso difícil, respeitando tanto a legislação, quanto os precedentes. Assim, na perspectiva de Ronald DWORKIN (1995, p. 102 e ss.), a regra jurídica não se constitui em um óbice ao cumprimento dos direitos individuais, mas num ingrediente que a ela se soma. Ao ser compreendida de forma mais aberta, a regra jurídica desmistifica-se, tornando-se uma fonte extraordinária de direitos morais (princípios).

Todas as ponderações acima colocadas surgem nos casos difíceis, nos quais há uma discordância acerca do critério a partir do qual as pretensões se estruturam. Através da interpretação, poder-se-ia superar a indeterminação ou vagueza que apresentam as regras, na medida em que se buscariam, através das mesmas, os princípios ou políticas que melhor agasalhassem as pretensões das partes.

O modelo de Ronald DWORKIN supõe que o juiz não se transforme em legislador, tendo em vista que o poder judicial tem como função garantir direitos préestabelecidos. Em segundo lugar, a tese de Ronald DWORKIN é compatível com o postulado da separação de poderes, tendo em vista que o juiz está subordinado à lei e ao Direito. Em terceiro lugar, o modelo da resposta certa rejeita a teoria do silogismo, mas aceita seu princípio político básico: o juiz não tem nem pode ter poder político. A função judicial é distinta da legislativa ou da executiva. Em quarto lugar, nos casos difíceis, os juízes não baseiam suas decisões em objetivos sociais ou diretrizes políticas. Os casos difíceis se resolvem com base em princípios que fundamentam direitos.

A atitude interpretativa atuará assim sobre a prática, alterando as formas originárias, reinterpretando-as sucessivamente. A interpretação supõe um momento préinterpretativo, no qual a natureza da prática é identificada. Neste estágio, o intérprete coleta regras, padrões e descrições do comportamento característico dos participantes e de suas atividades, os quais se constituem nos elementos da prática em questão.

Em seguida, ocorre a interpretação propriamente dita, cabendo ao intérprete buscar a melhor justificação possível à prática, cujos elementos foram identificados no primeiro momento. Aqui o intérprete propõe um valor para a prática, ao descrever um esquema de interesses ou objetivos aos quais a prática deve servir, expressar (DWORKIN, 1986, p. 52). A interpretação mostrará que a prática tem um apelo normativo, isto é, proporcionará uma justificação dos seus principais elementos e da sua participação nela (CHUEIRI, 1995, p. 105). 
O estágio pós-interpretativo ou reformador consiste no ajuste do sentido da interpretação, em face do que a prática exige para se adequar melhor à justificação aceita no estágio interpretativo. Isto não significa que a prática deva mudar, pois o que ocorre são visões conflitantes sobre o que a prática realmente é e o que realmente quer dos seus participantes como resultado.

Estes três estágios constitutivos da interpretação buscam, segundo Ronald DWORKIN (1986, p. 66), um equilíbrio entre a justificação da prática jurídica e suas exigências pós-interpretativas.

Segundo Ronald Dworkin, ter um Direito fundamental em um Estado de Direito, é ser titular de uma garantia jurídica forte, equivalente a ter um trunfo num jogo de cartas. A carta de trunfo prevalece sobre as outras, mesmo sobre as de valor facial mais elevado. A qualidade de trunfo, que lhe é reconhecida segundo as regras do jogo, bate a força do número, da quantidade, das cartas de outros naipes.

O jogador que senta do outro lado da mesa é o Estado, já que os direitos individuais são posições jurídicas em face do Estado. Ter um direito fundamental significa ter um trunfo contra o Estado, contra o governo democraticamente legitimado. É ter um trunfo contra a maioria que governa, mesmo quando esta decide segundo os procedimentos democráticos instituídos e dispõe do apoio de uma maioria social (NOVAES, 2012, p. 18).

\section{CONSIDERAÇÕES FINAIS}

Por todo o exposto, na obra de Aldous Huxley, os direitos fundamentais mínimos não eram respeitados, o que resta não apenas claro mas também explicitado quando analisada a obra utilizando como espelho a concepção de direito de Ronald Dworkin. Consequentemente, ausente a base principal para o Estado Democrático de Direito, que deverá pautar as sociedades contemporâneas, consoante se buscou demonstrar, dentro dos limites impostos pela presente publicação.

\section{BIBLIOGRAFIA}

CHUEIRI, Vera Karam de. Filosofia do Direito e modernidade: Dworkin e a possibilidade de um discurso instituinte de direitos. Curitiba: JM Editora, 1995. 
DWORKIN, Ronald. Law's empire. Londres: Fontana Press, 1986.

. El imperio de la justicia: de la teoría general del derecho, de las decisiones e interpretaciones de los jueces y de la integridad política y legal como clave de la teoría e práctica. 2. ed. Traduzido por Claudia Ferrari. Barcelona: Gedisa, 1992.

Los derechos en serio. Traduzido por Marta Guastavino. Barcelona: Ariel Derecho, 1995. . Taking Rights Seriously. Estados Unidos da América: Harvard University, 1997.

GRAU, Eros Roberto. A ordem econômica na Constituição de 1988: interpretação e crítica. 2. ed. São Paulo: Revista dos Tribunais, 1988.

GUERRA FILHO, Willis Santiago. Processo constitucional e direitos fundamentais. São Paulo: Celso Bastos, 1998.

HUXLEY, Aldous. Admirável Mundo Novo. Trad. Vidal de Oliveira. São Paulo: Globo, 2009.

NEVES, Antônio Castanheira. O Actual Problema Metodológico da Interpretação JurídicaI. Coimbra: Coimbra, 2003.

NOVAES, Jorge Reis. Direitos Fundamentais e Justiça Constitucional - Em Estado de Direito Democrático. Coimbra: Coimbra Editora, 2012.

ROCHA, Leonel Severo (org.); KOZICKI, Katya; et al. Paradoxos da auto-observação - percursos da teoria jurídica contemporânea. Curitiba: JM Editora, 1997.

(Artigo submetido em 02/06/2014 e aceito em 29/07/2014) 